\title{
Dynamic Assessment: A Complementary Method to Promote EFL Learning
}

\author{
Shifan Thaha Abdullateef \\ Department of English Language and Literature \\ College of Sciences and Humanities \\ Prince Sattam Bin Abdulaziz University \\ Alkharj, Kingdom of Saudi Arabia \\ Corresponding Author: s.abdullateef@ psau.edu.sa \\ Fatima Muhammedzein \\ Department of English Language and Literature \\ Al Qassim University, Kingdom of Saudi Arabia
}

Received: 3/30/2021

Accepted: 6/9/2021

Published:6/24/2021

\begin{abstract}
Although some assessment modes have proved successful, many learning problems encountered by low achieving learners need to be fixed by a more procedurally adequate remedial classroom assessment. Many EFL instructors adopt conventional and static modes of assessment rather than flexible and humanistic assessment modes. Hence, the study aims at examining how Dynamic Assessment that premises on Vygotsky's 'zone of proximal development and advocates mediation through good social setting and practice can enhance EFL language learning. Accordingly, 25 EFL students pursuing the first level of an undergraduate course at Prince Sattam bin Abdulaziz University, formed the experimental group for the writing task and 20 for the Reading task. Pre-test and post-test were administered based on Browns' Interventionist Model for writing task and Feuerstein's Interactionist model for Reading Comprehension. In addition, an online questionnaire was distributed to 43 university teachers from Prince Sattam bin Abdulaziz University to elicit their opinion. Data were statistically analyzed using SPSS. The results show a significant relation between Dynamic Assessment and language learning. The implications of findings will be helpful in EFL classrooms and research.
\end{abstract}

Keywords: dynamic assessment, EFL learning, interactionist, interventionist, mediation

Cite as: Abdullateef, S. T. \& Muhammedzein, F. (2021). Dynamic Assessment: A Complementary Method to Promote EFL Learning. Arab World English Journal, 12 (2) 279-

293. DOI: https://dx.doi.org/10.24093/awej/vol12no2.19 


\section{Introduction}

In the 21st century, English has become an indispensable part of the educational curriculum in non-native English-speaking countries, (Piekkari, 2009). However, most of the instructors find the process of EFL teaching /learning very challenging. A significant body of research has proved that different factors make it a complicated process, Akbari(2015). Although tremendous efforts have been exerted to improve the teaching-learning process of English, EFL programs still fail to deliver as expected, and the EFL learners' proficiency in English remains inadequate and below expectation (Fareh, 2010). Due to the negligence of the writing skill in the educational process and its challenging nature, writing is considered one of the most demanding skills for EFL students to learn. Grammar, spelling, punctuation, choice of words, organization, and familiarity with genres and rhetorical structures, negative transfer from native to the target language, and idiomatic expressions and collocations are the other factors that make the writing task difficult (Du, 2020; Derakhshan \& Shirejini, 2015). Concerning Reading skills, the challenge lies in terms of vocabulary, morphological and phonological awareness, ambiguous words, unfamiliar vocabulary, and limited available time to cognitively process the text (Qrqez \& Radzuwan, 2019). Unfortunately, most assessment techniques are product-oriented (evaluating the result or outcome based on descriptive scoring schemes). This type of assessment lacks solutions for low cognitive functioning and poor academic performance. Though assessment is an integral part of the teaching and learning process, for determining whether the learning goals are met or not, most of the institutions still prefer conventional Summative Assessments to grade students by spotting what the students know at a specified point in time. Learners are expected to memorize a lot of information and recall the information in written tests. Hence, student learning is gauged based on content standards without providing the opportunity to think creatively and take active participation in the learning process. In addition, in cases where the institutions provide flexibility to the instructors to design tests, most EFL teachers do not have adequate knowledge and skill to adopt new assessment systems. As a result, many learners excel, as examinations focus mainly on memorization and rote learning. On the contrary, they do not do well when exam questions involve creativity, critical thinking, or problem-solving. Needless to say that to a great extent, the washback effect (assessment affecting teaching materials) hinders the adaptation of instruction to support students' learning. Thus, it is imperative to think beyond the Static Assessment methods due to the following limitations as stated by (States, Detrich, \& Keyworth, 2018). First, they do not offer adequate information about learning processes and impaired cognitive functions that cause learning difficulties. Second, there is no provision for mediational strategies to facilitate learning. Therefore, due to rigid evaluation procedures, the learning potential of the low performers is either underestimated or ignored. Third, learners are described in general terms, and recommendations for prescriptive teaching and remedial learning strategies are not provided. In addition, static tests do not take into consideration the nonintellective factors i.e. intrinsic motivation, need for mastery, locus of control, anxiety, frustration, tolerance, self-confidence, and accessibility to mediation though these factors can to a great extent influence individual's cognitive performance. States et al. claim that Summative Assessment happens after instruction is over, and has little value as a diagnostic tool to guide teachers in making timely adjustments to instruction aimed at catching students who are falling behind. Hence, research finds little evidence to support it as a critical factor in improved student achievement as it does not provide teachers with vital information to use in designing remedial instruction. 


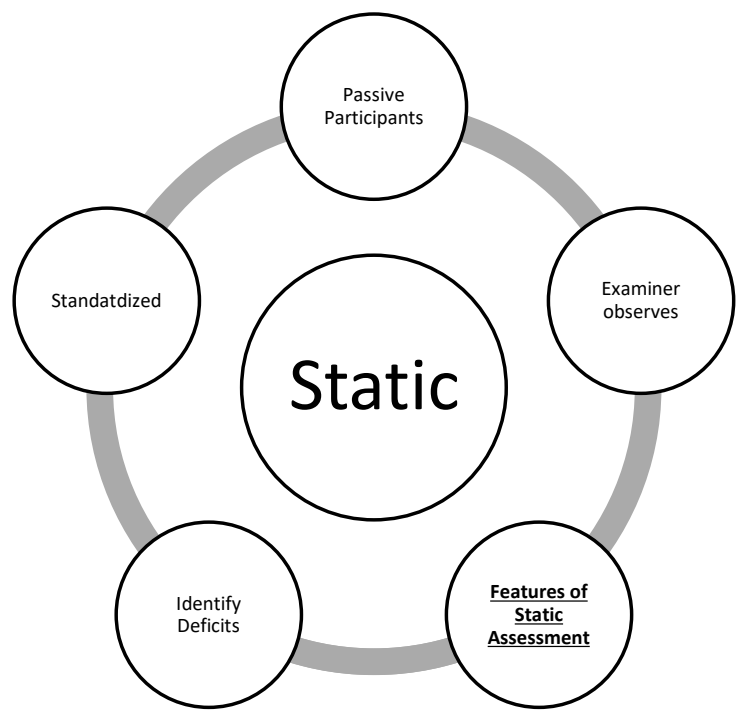

Figure 1. Features of static assessment

The limitations of Static Assessments led to a shift from product-oriented traditional tests to process-oriented methods of holistic testing approaches with the focus on real-life tasks thus, promoting the participation of students, their peers, and teachers.

\section{A Shift from Convergent to Divergent Techniques}

As a solution to the instruction-assessment dualism, Vygotsky (1978) evolved sociocultural theory and stressed the concept of Zone of Proximal /potential Development (ZPD). According to (Beddows, 2016), the theory is based on the assumption that there are three stages of ZPD: Stage one: Tasks the learners can do by themselves. Stage two: Tasks the learners can do with assistance. This category includes tasks a person can't work through by themselves but can work through with help, also known as their ZPD. Stage three: Tasks the learner cannot do even with assistance. This means the task is above their skill level and outside their ZPD. Thus, Beddows concludes that the Zone of proximal /potential development is the distance between the learner's current state of affairs and the next step. According to Vygotsky, cognitive abilities emerge from interactions in the world and are always mediated. Abilities do not mature on their own but instead result from individuals' histories of engaging in activities with others and with cultural artifacts. Vygotsky's socio-cultural theory stresses the fact that learners' abilities can be promoted by continually fine-tuning their mediation to the learners' changing needs. The Learning Theory Project Team at the University of Hongkong (2018), states that though Vygotsky (1978) did not use the term, 'scaffolding' while introducing the concept of the zone of proximal development, the use of scaffolding can be beneficial as it can be instrumental in pushing learners to accomplish complex and challenging tasks by adopting techniques, for instance, prompting, modeling or giving clues to provide enough support to achieve their proximal goals and gradually reducing the amount of aid as a learner's ability to complete a skill improves.

\section{Process Approach}

Irrespective of the specific abilities or interests of the learners it has been observed and recorded that when learners are provided with instructional designs with opportunities to actively 
process information by manipulating, deciding, solving, and predicting information in productive ways, learning becomes more meaningful and learner-centered, and has a huge impact on the attitudes, perceptions, and beliefs of the learners. Nabhan (2016) claims that the process writing approach plays a significant role in improving writing skills. Based on the sociocultural theory and ZPD in particular, (Shabani, 2016) points out that Static assessment is an incomplete and unethical way of assessing learners' abilities. Whereas, Dynamic Assessment crystallizes not only learner's levels of abilities in terms of independent (present) but also, assisted (potential) abilities. Therefore, 'Dynamic Assessment is not an alternative but complementary to traditional psychometric assessment'. In addition, Samran and Mehdi (2018) stressed the significance of Dynamic assessment as a method to investigate and highlight the individual learner's possessed skills and potential development. According to Estaji and Ameri (2020), Dynamic Assessment (DA) is an implicit kind of assessment that most teachers and learners engage in during the class time. Dynamic Assessment, a term coined by Luria in 1961 (as cited in Poehner \& Lantolf, 2010), is a kind of assessment that engages the teachers continuously whereby "assessment and instruction are a single activity" in which intervention is offered to diagnose and improve learner development at the same time. Estaji and Ameri claim that Dynamic Assessment (DA) is an assessment of a learner's perception, learning, thinking, and problem-solving, by an active teaching process. It aims to modify the learner's cognitive functioning and to observe subsequent changes in learning and problem-solving patterns within the testing situation. According to (Ebadi and Yari, 2018), in DA, a two-way interactive relationship is developed between the teacher and the learner and both parties could initiate questions. According to (Rahbardar, Abbasi \& Talaei, 2014), DA aims to a) assess the grasping capacity of the learner's principle underlying an initial problem and to solve it, (b) assess the nature and amount of teaching required to teach a learner a given concept, and (c) identify the specific deficient cognitive functions and non-intellective factors (i.e., need for mastery) that are responsible for low performance and how they can be modified modifiable by teaching. Thus, this method proved to be more beneficial than the static method of assessment and has been supported by a good number of researchers. For instance, Hidri (2019) proved that when compared to static assessment, the dynamic assessment was more effective as it improved the syntactic knowledge of the learners thereby developing the writing skills of the EFL students. Further, Adeline (2012) observed that DA procedures played a significant role in promoting learners' reading skills and realizing their learning potential.

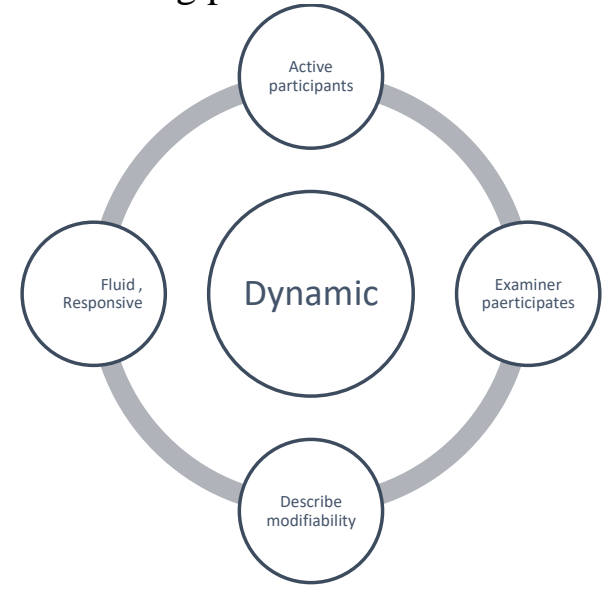

Figure 2. Features of dynamic assessment 
Thus, many researchers consider Dynamic Assessment to be instrumental in enhancing the productivity of the EFL learners and boosting confidence.

\section{Nature of Dynamic Assessment}

Haywood and Lidz (2007) mention that DA is can be considered as a complement to standardized testing and not a substitute for it. It is presented as a broad approach and not as a particular test. DA is a shift from the conventional tests in terms of goals, testing processes, instruments used, interpretation of results, and test situations. Moreover, the criteria of change are different in DA about pre-to post-teaching gains, amount and type of teaching required, and the degree of transfer of learning. Instead of adapting the conventional measures of intelligence, DA is based on predicting future cognitive performance and the outcome of intervention programs.

\section{Types of Dynamic Assessment}

According to Haywood and Lidz, Vygotsky's concept of a Zone of Proximal Development (ZPD) and Reuben Feuerstein's theory of Mediated Learning Experiences (MLE) served as the main conceptual bases for most of the DA elaboration. Dynamic assessment has different approaches. For instance: "graduated promptly", "testing the limit", and the "mediated learning experience". (Lantolf \& Poehner(2007, p. 35). However, they differ based on the approach towards mediation. Dynamic assessment leads to mediation to help learners to reconsider the problems and also think through them. It enables the mediator to recognize the level of learners' understanding of relevant linguistic features. Its emphasis is on instruction. During mediation, the role of the mediator is to comfort consensus-building discussion.

The two most common models of mediation are discussed below:

\section{Feuerstein's Interactionist Model}

Based on his experience with people with minimal education levels, Feuerstein concluded that human cognitive abilities are not fixed. Learners can develop their learning potential and can be classified through interventions i.e. performance can change through cognitive processes. Feuerstein (1978) claimed that Intelligence is not a static structure, but an open, dynamic system that can continue to develop throughout life. (According to his theory on Mediated Learning Experience (MLE), the learner keeps interacting with a more competent peer and selects, changes, amplifies and interprets the objects through mediations while the mediator expands, and interprets the learner's learning process. The theory also states that mere supervision and interaction between the learner and the instructor will not suffice the purpose. Therefore, the mediator is required to be a responsible, affectionate, knowledgeable, and competent intermediary between the learner and the mediated learning experience and must believe in their ability to change, making them see their learning potential. Thus, Feuerstein's model integrates assessment and instruction. The use of mediated learning as a way of integrating students into their environment consists of the transformation of all stimuli through an educator that orders them, organizes them, and modifies them to ensure a better understanding of the universe that surrounds them (Orru, 2003). 
Brown's Interventionist Model

This model is constructed based on the number of prompts required to extract the desired response. A student's learning potential is evaluated by the number of prompts needed to achieve the goal. Unlike, Feuerstein's model, mediation is ordered from most implicit to most explicit, resulting in a correct answer (Naeini \& Duvall, 2012).

\section{Sandwich Format}

Ebadi and Yari (2017) maintained that this type of intervention is also called the "pretestintervention/training-post-test" format. It has three stages: first, the pre-test, second, the mediation (instruction) stage finally, the post-test. As the mediation takes place between the pretest and post-test phases, this format is called Sandwiched instruction. This format includes both individualized and group mediation. However, for group mediation, the instructions are more implicit and for individualized mediation, the instructions are more explicit.

\section{Interventionist Cake Format}

Ebadi and Yari (2017) highlighted that in this format, graded prompt support is provided to the learners like icing on a cake. Learners are given a series of questions. They face the next question only when they answer the previous question properly Leipzig Learning Test (LLT) developed by Guthke can be considered as an example of a well-developed interventionist approach. It includes a set of five standardized prompts from implicit to explicit for all learners. The learner's performance is evaluated based on the number of prompts used time taken. According to Lantolf and Poehner (2007), due to its focus on standardization, interventionist DA has high reliability.

The researchers derived numerous valuable inputs from previous studies related to the development of language skills among EFL learners through Dynamic and Formative Assessments. For instance, Rashidi and Nejad (2018) investigated the effect of Dynamic Assessment on the EFL Learners' Process Writing development. The results showed the experimental group's dynamic assessment scores were higher than the control group's scores. Hence, it was concluded that Dynamic Assessment significantly influenced participants' scores, and enhanced their writing ability. The results of the learners' interview assured that dynamic assessment could improve the learners' EFL process writing and their confidence. It also elevated their motivation in their writing ability. The effectiveness of Dynamic Assessment has been further enunciated by Hidri (2019). In addition, (Jafary, Nordin, and Mohajeri, 2012), explored the effect of dynamic assessment on learners' syntactic knowledge. The main concern of the study was the significant difference between Dynamic and Static Assessment and the possible role of these two forms of Assessment on the syntactic development of EFL learners. The results showed that the performance of the experimental group was better than the control group. Jafary et al. concluded that Dynamic Assessment outperformed in improving the syntactic knowledge of the learners. In addition, Adeline (2012) conducted a study on the effects of Dynamic Assessment on College EFL Learners' Reading Skills. The study showed that appropriately designed DA procedures played a significant role in promoting learners' reading skills and realizing their learning potential. It is an accepted and acknowledged fact that for EFL learners, motivation plays a very vital role in the learning process. In their study on the effect of Dynamic Assessment on EFL Learners' Intrinsic Motivation, Zoghi and Malmeer (2013) concluded from 
the results that incorporation of DA as a supplement procedure to classroom activities has a positive effect on EFL learners' intrinsic motivation.

EFL learners find the target language to be very challenging. As a result, they require more guidance and extrinsic motivation than native speakers or ESL learners. Unfortunately, in traditional classrooms, instruction and assessment are not integrated. It is taken for granted that instruction is for the instructor and assessment is for the students. The success rate of learning is decided based on solo performance and grades are all that matter. The study stresses the fact that providing the learners with just the grades will not accelerate their learning and observance of solo performance is insufficient. This notion is supported by Kao (2020). The study states that one of the goals of language instruction is to support students' ability to transfer their learning or apply what they have learned in school to another setting. Similarly, Dimitrios and Athanasia(2019) investigated learners' creative potential through Dynamic Assessment and concluded that mediation significantly improved the creative potential of the learners.

Though Dynamic Assessment has great potential for EFL classroom practices, there is limited substantial research showing that Dynamic Assessment could be a suitable assessment system in EFL classrooms. According to Jiang (2020), classroom assessment has received a growing interest in recent decades. Classroom practices, however, heavily rely on teachers' knowledge and decision-making. Jiang states teacher assessment literacy becomes a fundamental factor that contributes to the effectiveness of classroom assessment. Therefore, the study aims to discuss the importance of Dynamic Assessment in the EFL learning context, emphasizing the origins and principal concepts involved in the process. The current study is helpful for instructors as it shows the importance of a shift from conventional and static modes of assessment to a more flexible and humanistic assessment mode.

To address the above-mentioned issues, the following research questions have been formulated: -Does Dynamic Assessment enhance EFL learning?

-In what sense does identification of learning gaps raise EFL learners' learning awareness?

-How do EFL teachers play an effective role in Dynamic Classroom Assessment?

\section{Methods}

\section{Participants and Research Procedures}

In addition to the literature reviewed above, a mixed approach was adopted. First, an experimental design was adopted to see the effect of the dynamic assessment on EFL learning. The data was obtained through results of the pre-tests and post-tests of 50 EFL students pursuing the First level of an undergraduate course at Prince Sattam bin Abdulaziz University and second, an online survey conducted for faculty, teaching different areas of English Language for the undergraduate students at Al Qassim University and Sattam Bin Abdulaziz University, Alkharj.

Mediation was based on Brown's (1982) Interventionist Model for Writing and Feuerstein's (1978) Interactionist model for Reading. In addition, the subjects' choice was justified by the consensus that teachers play a vital role and in fact, partake as mediators in the Dynamic Assessment process. The total number of respondents was 44. The questionnaire comprised of 17 statements, and a 5-point Likert scale was used to measure. The scope of the questionnaire centered around the study research questions. A few statements investigated participants' 
opinions regarding the possibility/impossibility of augmenting language learning via Dynamic Assessment, a few focused on knowledge of learning gaps and learning awareness, while other statements revolved around the responsibility of instructors in Dynamic Assessment. Nine statements were made positive, while six were negative. The data was statistically analyzed using One-Sample $\mathrm{T}$ (test) and percentages. The section below presents data analysis and interpretation.

\section{Research Instruments}

To conduct this study, the research method design took the form of a sandwich format by Sternberg and Grigorenko (2002). First, the participants took a traditional static test as a pre-test where no mediation was provided. Second, the mediation was provided to the participants and, finally, a post-test was conducted. The design enabled the researchers to compare the participant's performance before and after the mediation. Also, during the mediation phase, each participant was given time to record the reading strategies and reflections in the working portfolio.

The following steps were followed in the Essay Writing and Reading Sessions Step1. Pre-testing: The Writing course class comprised 50 students. Students were equally divided into two groups. Twenty-five students were part of the experimental group and the remaining 25 formed the control group. The pre-test was taken by both groups. The purpose of pre-testing was threefold as suggested by Estaji and Ameri (2020). First, to check the students' level of Writing skills before the course second, to determine the areas of difficulty in the experimental group, and finally, to examine whether the learners in the experimental and control groups were homogeneous regarding their writing abilities. Learners' pre-tests were corrected and scored (on a scale ranging from zero to15).

\section{Step Two: Treatment (Intervention)}

The researchers focussed on the experimental group. Based on the students' errors in the pretest, the researchers first, provided comments and explicit explanations second, identified the areas of difficulty to deal with separately using DA techniques. By Haywood and Lidz (2007) and as mentioned by Estaji and Ameri (2020), twenty to thirty minutes from three sessions were reserved for incorporating Dynamic Assessment.

\section{Sample of the Intervention in the First Session}

The learners were asked to write a composition of about 300 words. The question assigned to them was: How would you like to rejuvenate yourself this summer?

Hints/prompts and implicit explanations were provided to the learners based on Browns' Interventionist Model. 


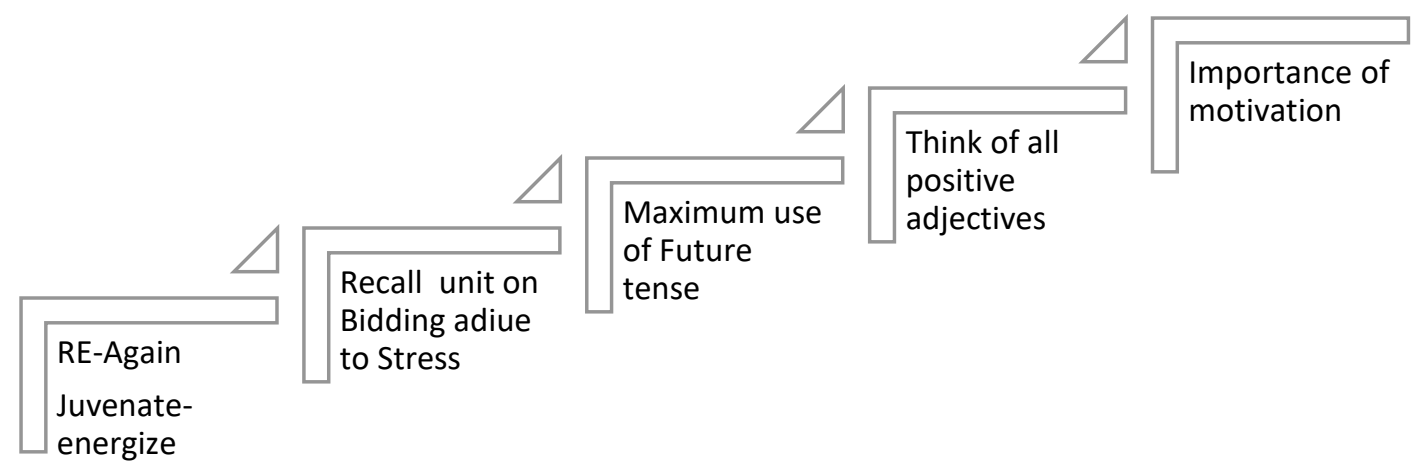

Figure 3. Intervention model: Clues for writing task

\section{Stage Three: Post-testing}

In the two sessions, the students in both groups took the post-test, the purpose of which was twofold as suggested by Estaji and Ameri (2020), first, to measure the possible differences in the achievement of the learners, and second, to compare the differences between the learners of the two proficiency levels. Opportunities were provided for self-correction and peer correction. The post-tests were corrected and scored on a scale ranging from zero to 15 . To investigate the general writing performance between two groups (control \& experimental) in the post-test writing stage, an independent sample t-test was conducted on SPSS.

\section{Results}

Table 1. Group-sample statistics

\begin{tabular}{|c|c|c|c|c|}
\hline Groups & $\mathrm{N}$ & Mean & Variation & Std. Deviation \\
\hline Control & 25 & 10.52 & 1.06581 & 34.2400 \\
\hline Experimental & 25 & 13.12 & 1.95399 & 38.6400 \\
\hline
\end{tabular}

Table one shows that the mean score of the control group is 10.52 , whereas the mean score of the experimental group is 13.12. The results of the study indicate that dynamic assessment significantly influenced participants' scores and improved their writing ability. Twenty out of Twenty-five learners considered interventions to be effective they could write an organized composition once they received support and guidance. Three of twenty-five learners revealed that for the first time they had completed their writing task only because of the support they received through this method. One out of twenty-five learners found this approach a bit difficult. Although she managed to write in an organized way, yet it was to some extent challenging. Three high scorers revealed that the approach was not very useful as they have been intrinsically motivated to take up challenges and tried to improvise without taking much support and guidance. Thus, the results indicate that learners' potential can be tapped and enhanced through interventions.

The researchers adopted Feuerstein's Interactionist model in two Reading Sessions as it supports learning and especially caters to the cultural difference.

Step One: Pre-testing

The Reading course class comprised 40 students. Students were equally divided into two groups. 20 were part of the experimental group and the remaining 20 formed the control group. 
Both groups took the pre-test. The purpose of pre-testing was threefold as suggested by Estaji and Ameri (2020): First, to check the students' level of comprehending before the course second, to determine the areas of difficulty in the experimental groups, and third, to examine whether the learners in the experimental and control groups were homogeneous regarding their reading abilities. Eventually, learners' pre-tests were corrected and scored (on a scale ranging from zero to15).

\section{Step Two: Treatment (Interaction)}

The researchers focussed on the experimental group. Based on the students' mistakes in the pre-test, the areas of difficulty were identified and then dealt with separately using DA techniques from the sessions for 20 minutes. In two sessions the following questions were discussed with the students in the form of interaction.

Do you think an image at the beginning of a passage could help you in comprehending the text? How?

$>$ Can we apply the same strategy to get different types of information from the passage?

$>$ What should we do when we come across a new word and do not understand its meaning?

$>$ When a comprehension passage is given should we read the passage first or the questions?

$>$ What should we do if we come across a very lengthy word?

$>$ Is it always essential to know the meaning of every word included in the passage

Stage Three: Post-testing

In the two sessions, the students in both groups took the post-test, the purpose of which was twofold: first, to measure the possible differences in the comprehension abilities of the learners in the groups second, to compare the differences between the learners of the two proficiency levels. Opportunities were provided for self-correction and peer correction. The post-tests were corrected and scored on a scale ranging from zero to 15 . To investigate the comprehension performance between two groups (control \& experimental) in the post-test stage, an independent sample t-test was conducted on SPSS.

Table 2. Group-sample statistics

\begin{tabular}{|c|c|c|c|c|}
\hline Groups & $\mathrm{N}$ & Mean & Variation & $\begin{array}{c}\text { Std. } \\
\text { Deviation }\end{array}$ \\
\hline Control & 20 & 10.30 & -1.42109 & 18.2000 \\
\hline Experimental & 20 & 12.45 & 1.42109 & 24.9500 \\
\hline
\end{tabular}

Table two indicates that the mean score of the control group is 10.30 whereas, the mean score of the experimental group is 12.45. From the difference, it is evident that learners' comprehension abilities could be enhanced through interactions. The results indicate that appropriately designed DA procedures could play a significant role in promoting learners' reading skills and realizing their learning potential. Students revealed that through interaction they could get a clear idea about the procedure to be followed and appropriate reading strategies to be applied to comprehend the text and extract different types of information. 


\section{Interview Protocol}

RQ1.To answer the first question: Does dynamic assessment enhance language learning? , the researchers conducted a $(\mathrm{T})$ test for the average of one community. The following table shows the result of the procedure.

Table 3. One-sample statistics and one-sample test

\begin{tabular}{|c|r|c|c|c|r|l|}
\hline Mean & Std. Deviation & $\begin{array}{c}\text { Test } \\
\text { Value }\end{array}$ & T & Df & Sig. (2-tailed) & Result \\
\hline 48.6364 & 4.46741 & 45 & 5.399 & 43 & .000 & High \\
\hline
\end{tabular}

Table three reveals the result of the (T) test for the average of one community to judge whether dynamic assessment boosts language learning or not.

It is clear from Table three that the calculated value of (T) was (5.399) at the level of statistical significance (000.), this indicates a high level of dynamic assessment elevates language learning. This result testifies the first study question and supports Hidri (2019), Samran and Mehdi (2018), Naeini and Duvall (2012); Adeline (2012). Fifty-four percent of respondents advocated teachers discussing with students learning improvement, and $52.3 \%$ agreed with teachers discussing with students doing complex tasks. However, $43.2 \%$ disfavored avoiding giving students more challenging tasks to be done independently. The researchers observed the learner moved well between tasks within the zone of proximal development and maintained the potentials to perform complex tasks without assistance.

RQ2. To answer the second question: In what sense does identify learning gaps raise learners' learning awareness?, the researchers conducted a (T) test for the average of one community, and the following table shows the result of the procedure.

Table four indicates that the result of the (T) test for the average of one community to judge 'How does identify learning gaps raise learners' learning awareness.'

Table 4. One-sample statistics and one-sample test

\begin{tabular}{|c|c|c|c|c|c|c|c|}
\hline $\mathrm{N}$ & Mean & $\begin{array}{c}\text { Std. } \\
\text { Deviation }\end{array}$ & $\begin{array}{c}\text { Test } \\
\text { Value }\end{array}$ & $\mathrm{T}$ & Df & $\begin{array}{c}\text { Sig. (2- } \\
\text { tailed) }\end{array}$ & Result \\
\hline 44 & 28.2045 & 2.99286 & 21 & 15.968 & 43 & .000 & High \\
\hline
\end{tabular}

Table four shows that the calculated value of (T) was (-15.968-) at the level of statistical significance (000.), indicating an increase in the level of developing learners' awareness through identifying learning gaps. The result testifies to the second study question. Moreover, (50\%) respondents agreed, and (45.5\%) strongly agreed that learners should identify the problems they face in learning a particular task or a learning material. Forty-eight percent ascertained the importance of asking questions to probe student's knowledge. $61.4 \%$ agreed that the questions must be sequential, starting from what the students know. The results are in line with Naeini and Duvall (2012). 
RQ3.To answer the third question: How do teachers play an influential role in dynamic classroom assessment?

Table five reveals that the result of the (T) test for the average of one community to judge 'How do teachers play an influential role in dynamic classroom assessment.

Table 5. One-sample statistics and one-sample

Test

\begin{tabular}{|c|c|c|c|c|c|c|}
\hline Mean & $\begin{array}{c}\text { Std. } \\
\text { Deviation }\end{array}$ & Test Value & $\mathrm{T}$ & $\mathrm{Df}$ & $\begin{array}{c}\text { Sig. (2- } \\
\text { tailed) }\end{array}$ & Result \\
\hline 28.3864 & 2.48919 & 24 & 11.689 & 43 & .000 & High \\
\hline
\end{tabular}

Table five demonstrates that the calculated value of (T) was (-11.689-) at the level of statistical significance (000.), this indicates a high level of teacher role in dynamic assessment. The result testifies the third study question, for the teacher mediates as interventionist and interactionist to improve learning by providing sequential prompts. Rashidi and Najed (2018), Adeline (2012), Dimitrios and Athanasia (2019), recommend this tendency. As per the results, $59.1 \%$ of respondents agreed with devoting instructional time during classes to fill learning gaps, and $56.8 \%$ of respondents preferred giving all the instructions at a time for a specific task. However, the researchers favor ordering instructions to promote learning. $75 \%$ of respondents disagreed with avoiding providing individual support to low achievers. Nevertheless, some added, "it depends on the abilities of individual students". $61.4 \%$ of respondents were against discouraging advanced students from helping less advanced peers as the interaction between the low and advanced learners is beneficial.

\section{Discussion}

The present study examines the significance of Dynamic Assessment in raising learners' learning, and the role of the instructors in enhancing the learning and tapping the potential of the learners to face the challenges of the 21st century. The results are in line with the observations of Adeline (2012) that Dynamic Assessment helps in assessing the present abilities and identifying the potential abilities of the learners. The instructor should acknowledge the fact that each learner possesses a special skill set and should look out for different means to identify the skills and hone them further. This, to a great extent, will instill confidence among the learners and eventually lead to their potential development. Further, the results and the findings are in line with the Feuerstein theory (1978), which states that abilities are not fixed. Skills development is an ongoing process and can develop through mediation and interactions among peers. The more the learners get exposure to experiences the stronger are the chances of developing their skills.

The research findings point towards Brown's notion of intervention and prompting by teachers, Nadine and Duvall (2012). The results of the questionnaire distributed to the faculty revealed that most of them prefer to intervene and give clues as guidance to channelize the thoughts of the learners and prevent digressions, disinterestedness, and demotivation, especially in the EFL context. This does not mean that the instructors make the learners too dependent or indulge in passive learning as considered by a good number of teachers with non-progressive mindsets who believe that learners should be seldom advised about what they need to do and left on their own. This kind of attitude can harm the learners. It draws a line between the 
responsibilities of the instructors and the learners. It is to be realized by the instructors that they are a part of the learning process and cannot demarcate their roles and boundaries. The role of the instructors also leads to another factor stressed by Zoghi and Malmeer(2013). The results and the findings are in line with the fact that EFL learners, especially require intrinsic and extrinsic motivation at different stages of learning. Limited exposure and opportunities are the root cause for their lack of confidence and anxiety, eventually leading to dropouts and passive learning. Not hand holding but, constant expression of acknowledgment, concern, and guidance can have a remarkable influence on the performance and personality of the learners. The results agree with Dimitrios and Athanasia (2019) that learner's creative potential enhances through motivation. It gives the learners a push to exhibit their talent with an expectation to be appreciated and applauded, as is the human tendency. Rashidi and Najed (2018) and Hidri (2019) concluded that Dynamic Assessment had a positive impact, especially on the syntactic forms which are considered as a major challenge by the EFL learners due to remarkable differences in the syntactic pattern between Arabic and English. The learners at Prince Sattam University and Qassim University showed improvements in their writings. The instructors who were a part of the study witnessed the difference in the quality of writing with, and without guidance. Thus, the researchers conclude that Dynamic Assessment stimulates learning and is more humanistic in approach as stated in the referred studies.

\section{Conclusion}

The present study set out to investigate the effects of interactionist and interventionist models of Dynamic Assessment on 50 EFL students pursuing the First level of an undergraduate course at Prince Sattam bin Abdulaziz University. The study concludes that Dynamic Assessment has a positive effect on language learning. Findings confirm the hypothesis of the study: proper mediation in identifying learning gaps and treatment via intervention and interaction gives classroom assessment potential to enhance student learning. In today's competitive job market, primary importance is being given to skills and practical experience rather than mere academic grades. As part of the selection process, many organizations are conducting tests to identify the potential abilities of the candidates. Therefore, the instructors must shift from convergent to divergent ways of assessments thereby, not only testing current abilities but also tapping potential abilities and honing the skills. Instructors need to be very much a part of the learning process of the learners of which assessment is an essential component. The instructors have to be extra involved, especially with EFL learners, as traditional ways of assessing target language do not provide a fair chance to the learners to display their skills. Anxiety, lack of confidence, confusion cannot be overlooked as these internal factors can act as a hindrance. Positive and constructive feedback to a great extent could boost learning. Hence, negative feedback should be avoided as it could prove to be detrimental to the learning process. Through constant guidance and support could be harmful yet, direction at the right time and in a proper way could enhance the learners' productivity by boosting their morale. However, the instructors should at the same time provide ample opportunities to the learners to develop their metacognition strategies. Thus, EFL instructors in specific and all instructors, in general, will have to identify interesting ways of assessing learners to enable them to display their talent, skills, and challenges.

\section{Implications of the Research}

Dynamic Assessment both as a concept and as a practice remains in need of substantial development, especially in EFL contexts. Further development is imperative in terms of process 
assessment. The need of the hour is to promote intensive study and development of research related to learners' approach towards learning tasks and inferential methods based on deliberate attempts to produce change. Another area for consideration is bridging the gap between learning assessment and classroom instruction and minimizing the problems of reliability and validity.

\section{About the Authors:}

Dr. Shifan Thaha Abdullateef is an Associate Professor of Applied Linguistics at the Department of English, Prince Sattam Bin Abdulaziz University, Al-Kharj, Saudi Arabia. She holds rich experience in diverse educational setups. Her research interests include EFL, Methods of teaching, Curriculum Designing, and CALL. ORCID ID: https://orcid.org/ 0000-0002-23214904

Dr. Fatima Muhammedzein, is an Assistant Professor of Linguistics at the Department of English, Al Qassim University, Saudi Arabia. Her research interests include Linguistics, EFL, Research Methods and Curriculum Designing.

\section{References}

Adeline, T. (2012). Effects of Dynamic Assessment on College EFL Learners' Reading Skills. The Journal of Asia TEFL, 9(1), 57-94.

Akbari, Z. (2015). Current Challenges in Teaching/Learning English for EFL Learners: The Case of Junior High School and High School, The Case of Junior High School and High School. Procedia - Social and Behavioral Sciences, 199, 394-401.

Beddows, C. (2016). Vygotsky's Theory (VT) of Cognitive Development: Sociocultural Orientation.

Available at http://scitechconnect.elsevier.com/vygotsky-cognitive-development/

Brown, W.R. (1982). Attention and the Rhetoric of Social Intervention. Quarterly Journal of Speech, 68, 17-27.

Derakhshan, A., \& Shirejini, R. K. (2015) .Implications of Dynamic Assessment in Second/Foreign Language Contexts. English Linguistics Research, 4(1),41-48

Dimitrios, Z, \& Athanasia, T. (2019).Investigating Primary School Childrens' Creative Potential through Dynamic Assessment. Frontiers in Psychology, 10, 733. https://doi.org/10.3389/fpsyg.2019.00733

Du, J. (2020). Non-native English-speaking engineers' writing at the workplace. Shanghai Jiao Tong University Press; Springer.

Ebadi, S., \& Yari, V.(2017). Investigating the Effects of Using Dynamic Assessment Procedures on the EFL Learners' Vocabulary Knowledge. Journal of Modern Research in English Language Studies, 4(3), 49-72.

Estaji, M., \& Ameri, A. (2020). Dynamic Assessment and its impact on pre-intermediate and high-intermediate EFL learners' grammar achievement, Cogent Education, 7(1) https://doi.org/10.1080/2331186X.2020.1740040

Fareh, S . (2010). Challenges of teaching English in the Arab world: Why can't EFL programs deliver as expected?.Procedia - Social and Behavioral Sciences, 2(2), 3600-3604.

Feuerstein, R. F. (1978). Dynamic Assessments Of Cognitive Modifiability. Jerusalem: ICELP Press.

Haywood, H., C., \& Lidz, C.S. (2007). Dynamic assessment in practice: Clinical and educational applications. Cambridge University Press. 
https://www.researchgate.net/publication/280559778_Dynamic_Assessment_in_Practice _Clinical_and_Educational_Applications

Hidri, S. (2019). Static vs. Dynamic Assessment of students' writing exams: a comparison of two assessment modes. International Multilingual Research Journal, 13(4), 239-256. https://doi.org/10.1080/19313152.2019.1606875

Jafary, R.M., Nordin, N., \& Mohajeri, R.(2012). The Effect of Dynamic versus Static Assessment on Syntactic Development of Iranian College Preparatory EFL Learners.English Language Teaching, 5(7), 7-16. https://doi.org/10.5539/elt.v5n7p149

Jiang, Y. (2020). Teacher Classroom Questioning Practice and Assessment Literacy: Case Studies of Four English Language Teachers in Chinese Universities. Frontiers in Education.

Kao, Y. A.(2020). Comparison Study of Dynamic Assessment and Non-dynamic Assessment on EFL Chinese Learner's Speaking Performance: Transfer of Learning. English Teaching \& Learning,44, 255-275. https://doi.org/10.1007/s42321-019-00042-1

Lantolf, J. P., \& Poehner, M. (2007). Dynamic Assessment in the Foreign Language Classroom: A Teachers' Guide. Pennsylvania: Caliper Publications.

Nabhan, S. (2016). The Process Approach to Improve Students' Writing Ability in English Education Department University of Pgri Adi Buana Surabaya. Jembatan Merah, Jurnal Pengajaran Bahasa dan Sastra. 13, 1-15.

Naeini, J., \& Duvall, E.(2012).Dynamic Assessment and the Impact on English Language Learners' Reading Comprehension Performance. Language Testing in Asia, 2(2) https://doi.org/10.1186/2229-0443-2-2-22

Piekkari, R. (2009). International Management. In F. Bargiela- Chiappini (Ed.), The Handbook of Business Discourse .269-278.

Qrqez, M., \& AbRashid, R. (2019).The Sources of Reading Comprehension Difficulties among Saudi EFL Learners. Trends in Social Sciences, 1(1), 7-16.

Rashidi, N., \& Najed, B. (2018). An Investigation into the Effect of Dynamic Assessment on the EFL Learners' Process Writing Development. SAGE Open

Samran, M., \& Mehdi, M. (2018).Dynamic Assessment in Vygotsky's Sociocultural Theory: Origins and Main Concepts. Journal of Language Teaching and Research. (9)

Shabani, K.(2016).Implications of Vygotsky's sociocultural theory for the second language (L2) assessment. Cogent Education, 3(1) , 600-607. https://doi.org/10.1080/2331186X.2016.1242459

States, J., Detrich, R., \& Keyworth, R. (2018). Overview of Summative Assessment. Oakland, CA: The Wing Institute.

Available at https://www.winginstitute.org/assessment-summative.

Sternberg, R. J., \& Grigorenko, E.L. (2002). Dynamic Testing: The nature and measurement of learning potential. Cambridge: Cambridge University Press.

Vygotsky, L. S. (1978). Mind in Society. Cambridge, MA: Harvard University Press. Available at https://kb.edu.hku.hk/theory_social_constructivism/

Zoghi, M., \& Malmeer, E. (2013). The Effect Of Dynamic Assessment On EFL Learners Intrinsic Motivation. Journal of Language Teaching and Research, 4(3), 584-591. 